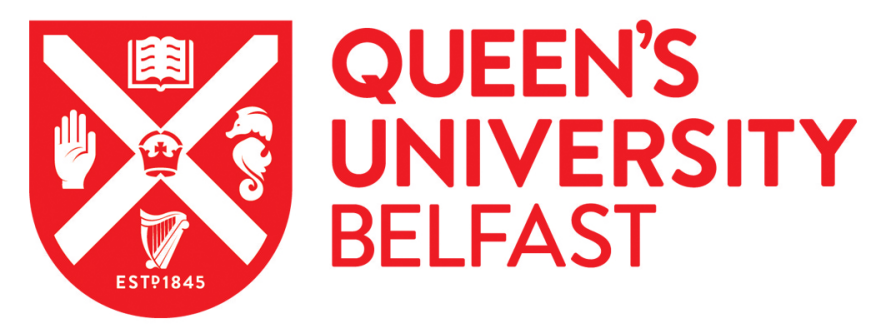

\title{
Methods of calculating prostate-specific antigen velocity
}

Connolly, D., Black, A., Murray, L., Napolitano, G., Gavin, A., \& Keane, P. F. (2007). Methods of calculating prostate-specific antigen velocity. European Urology, 52(4), 1044-1051.

https://doi.org/10.1016/j.eururo.2006.12.017

Published in:

European Urology

Queen's University Belfast - Research Portal:

Link to publication record in Queen's University Belfast Research Portal

\section{General rights}

Copyright for the publications made accessible via the Queen's University Belfast Research Portal is retained by the author(s) and / or other copyright owners and it is a condition of accessing these publications that users recognise and abide by the legal requirements associated with these rights.

Take down policy

The Research Portal is Queen's institutional repository that provides access to Queen's research output. Every effort has been made to ensure that content in the Research Portal does not infringe any person's rights, or applicable UK laws. If you discover content in the Research Portal that you believe breaches copyright or violates any law, please contact openaccess@qub.ac.uk. 


\title{
Methods of Calculating Prostate-Specific Antigen Velocity
}

\author{
David Connolly ${ }^{a, b, *}$, Amanda Black ${ }^{b}$, Liam J. Murray $^{b}$, Giulio Napolitano $^{c}$, \\ Anna Gavin c, Patrick F. Keane ${ }^{a}$ \\ a Department of Urology, Belfast City Hospital, Belfast, Northern Ireland, United Kingdom \\ ${ }^{\mathrm{b}}$ Cancer Epidemiology \& Prevention Research Group, Queen's University Belfast, Belfast, Northern Ireland, United Kingdom \\ ${ }^{c}$ Northern Ireland Cancer Registry, Queen's University Belfast, Belfast, Northern Ireland, United Kingdom
}

\section{Article info}

Article history:

Accepted December 11, 2006

Published online ahead of print on December 18, 2006

\section{Keywords:}

Calculation

Linear regression

Method

PSA

PSA velocity

\begin{abstract}
Objectives: Numerous methods of calculating PSA velocity (PSAV) are used and have the potential to produce differing PSAV results from the same PSA data. We calculated PSAV using three common methods and compared differences between the methods and their predictive value for prostate cancer diagnosis.

Methods: From a population-based database of PSA results, men with initial PSA $<10.0 \mathrm{ng} / \mathrm{ml}$ and a subsequent diagnosis of prostate cancer or benign histology were identified. Those with $\geq 3$ PSA tests before diagnosis carried out over a minimum of 18 mo were included. PSAV was calculated by using three methods:
\end{abstract}

1. Arithmetic equation of change in PSA over time (AE)

2. Linear regression (LR)

3. Rate of PSA change using first and last values only (FL)

The differences between the methods and test characteristics of each method were compared.

Results: Of the 2204 men included, 716 (32.5\%) were diagnosed with prostate cancer and 1488 (67.5\%) benign histology. PSAV differed markedly in each method of calculation. The LR and FL methods had similar predictive values, which were higher than the AE method. There was strong agreement for cancer diagnosis between LR and FL (kappa $=0.85$ ), with weaker agreement between LR/AE and FL/AE (kappa $=0.69$ and 0.66, respectively).

Conclusions: Methods used to calculate PSAV using the same PSA data can produce markedly different results. Linear regression should be the method of choice for calculating PSAV. Using first and last PSA values only may be adequate for everyday clinical use, as long as measurements are separated by a sufficiently long time period.

(c) 2006 European Association of Urology. Published by Elsevier B.V. All rights reserved.

* Corresponding author. Department of Urology, Belfast City Hospital, Lisburn Road, Belfast, Northern Ireland BT9 7AB, United Kingdom. Tel. (+44) 07817209863 (mobile), (+44) 02890632686 (work),(+44) 02891270133 (home); Fax: (+44) 02890248017. E-mail address: djconn76@hotmail.com, dconnolly02@qub.ac.uk (D. Connolly). 


\section{Introduction}

Prostate-specific antigen (PSA) remains the best available biomarker for the detection of prostate cancer [1]; however, it has limitations as a diagnostic test. The majority of men with a PSA of $<10.0 \mathrm{ng} / \mathrm{ml}$ have benign disease and not prostate cancer [2]; therefore, a large number of men may proceed to unnecessary invasive investigations. The rate of change in PSA over time (PSA velocity) may have advantages over a single PSA measurement in differentiating between men with prostate cancer and those with benign disease [3-6]. PSAV was originally described by Carter et al [3] who found, using a PSAV cutoff of $0.75 \mathrm{ng} / \mathrm{ml} / \mathrm{yr}$, a sensitivity of $72 \%$ and a specificity of $95 \%$ for prostate cancer diagnosis. Although these findings have since been confirmed by others [4,5], the optimal cutoff remains controversial, particularly at low PSA levels $[4,7,8]$. Contrary to these studies, others have reported that PSAV has little additional benefit over a single PSA cutoff [9-11]. The conflicting evidence from these reports may relate to variation in the populations studied, although a possible contributing factor may be that the method of PSAV calculation was not standardised. The many methods used to calculate PSAV have the potential to produce differing results from the same PSA data. Within a large populationbased data set, we calculated PSAV using three commonly used methods and compared the differences between the methods and each method's test characteristics.

\section{Methods}

\subsection{Study population}

Northern Ireland (NI) has a population of approximately 820,000 men, 220,000 (26.6\%) of whom are older than $50 \mathrm{yr}$ [12]. Analysis of PSA tests in the region is performed in 10 laboratories with the use of a variety of immunoassays. The Northern Ireland Cancer Registry (NICR) maintains a confidential electronic database of all PSA results for prostate cancer surveillance purposes. Using unique identifiers (name, date of birth, address), PSA results were matched to identify repeat tests for each individual. These data are routinely linked to hospital discharge and histopathology data to identify men who have been diagnosed with prostate cancer or histologically confirmed benign disease (biopsy and transurethral resection of the prostate). Although PSA screening for prostate cancer is not recommended in NI, there is recent evidence of increasing opportunistic screening within the region [13].

All patient identifiable information was removed before the research team accessed the data used in this study; no patient contact was made during the study. Therefore, ethical approval was not sought.
All men with initial PSA of $<10.0 \mathrm{ng} / \mathrm{ml}$, taken between 1 January 1994 and 31 December 2003, and a subsequent diagnosis of prostate cancer or benign histology made before 31 December 2003 were identified. Those with at least three PSA tests before diagnosis performed over a minimum of 18 mo were included in this analysis [14]. PSAV was calculated as the rate of change of PSA by using three methods (Fig. 1):

1. Arithmetic equation of change in PSA over time (AE), using the equation: $[1 /(n-1)] *\left(\sum_{i=2}^{n} p_{i}-p_{i-1} / t_{i}-t_{i-1}\right)$

2. Linear regression (LR) analysis, using all PSA values and the equation: $p=a t+b$
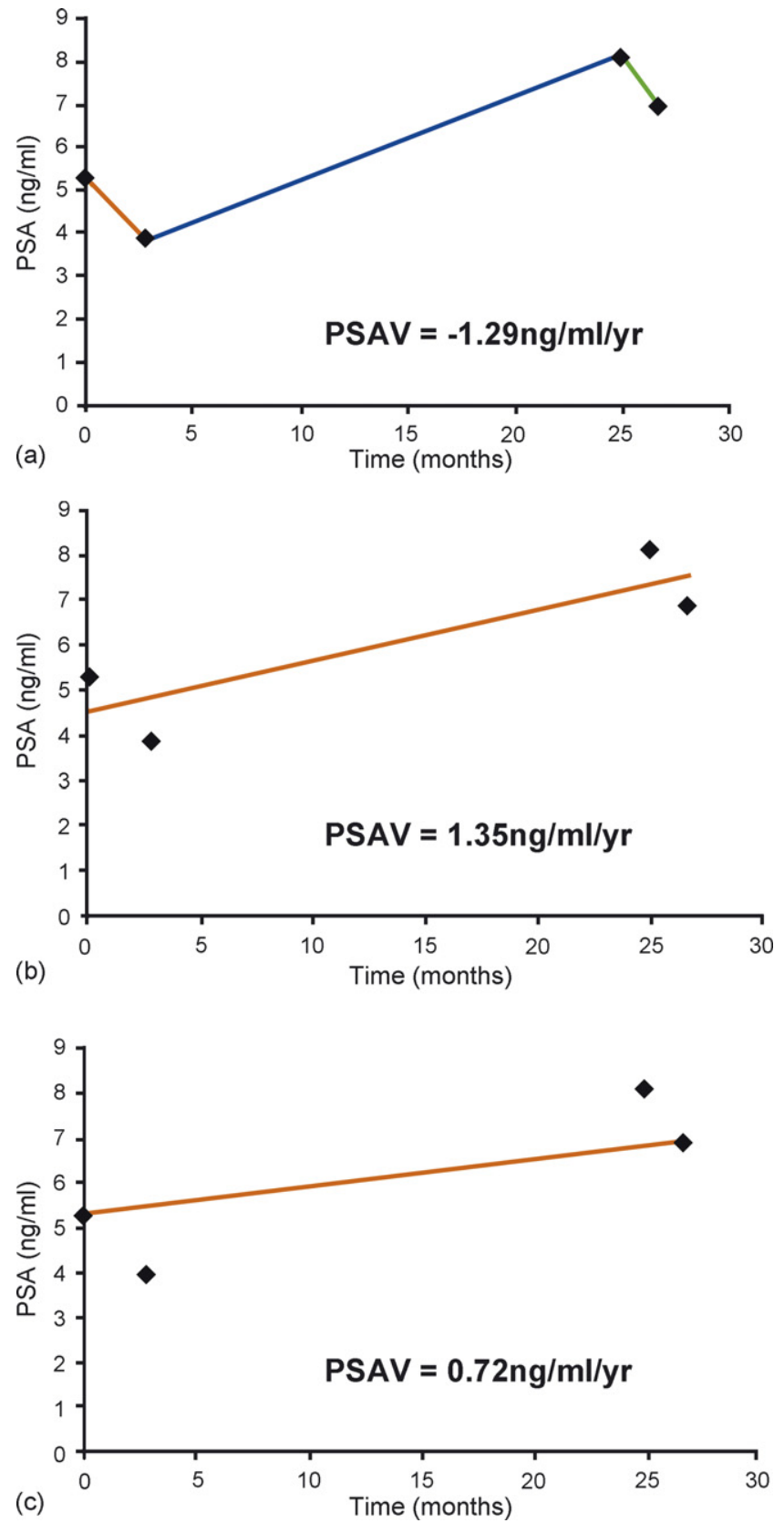

Fig. 1 - Prostate-specific antigen (PSA) velocity calculated by three methods in a 51-year-old man diagnosed with prostate cancer: (a) arithmetic equation; (b) linear regression; (c) first and last only. 
3. Rate of PSA change using first and last values only (FL) and the equation: $p_{n}-p_{1} / t_{n}-t_{1}$

where $n=$ total number of PSA tests, $\sum=$ sum of, $p=$ PSA value, $t=$ time at PSA test (yr), $a=$ slope of regression line (equivalent to PSAV), and $b=$ intercept at time zero.

\subsection{Statistical analysis}

PSAV was calculated by each of the three methods for the following groups: (1) all men, (2) men diagnosed with prostate cancer, and (3) men diagnosed with benign disease. The mean and median PSAVs calculated by each method were compared in men with cancer to those with benign disease by using the unpaired $t$ test and Mann-Whitney $U$ test, respectively. For each individual, the difference between the PSAV values calculated by each method was determined (ie, FL - LR, FL - AE, and $L R-A E)$. The mean and median of these differences were then compared by using the paired $t$ tests and Wilcoxon signed rank methods, respectively.

To assess the level of agreement between the PSAVs calculated by each method and prostate cancer diagnosis,
PSAV was dichotomised to above or below $0.75 \mathrm{ng} / \mathrm{ml} / \mathrm{yr}$ and tested by using the kappa statistic.

The sensitivity, specificity, and positive and negative predictive values for PSAV cutoffs of $0.75 \mathrm{ng} / \mathrm{ml} / \mathrm{yr}$ and $0.0 \mathrm{ng} / \mathrm{ml} / \mathrm{yr}$ for prostate cancer diagnosis were calculated. To compare the operating characteristics of each method, PSAV was categorised into 22 groups: $<0.0 \mathrm{ng} / \mathrm{ml} / \mathrm{yr}, 0.0-0.1$ (increasing in increments of 0.1 up to 2.0 ), and $\geq 2.0 \mathrm{ng} / \mathrm{ml} / \mathrm{yr}$. The equality of the area under the receiver operator characteristic (ROC) curves obtained for each of the methods was tested. All statistics were performed with Intercooled Stata, version 8.0 (Stata Corp, College Station TX, USA).

\section{Results}

Of the 2204 men included, 716 (32.5\%) were diagnosed with prostate cancer and 1488 (67.5\%) had benign histology. The group characteristics are shown in Table 1. Mean age was higher in men diagnosed with cancer compared with benign

\section{Table 1 - Group characteristics}

\begin{tabular}{|c|c|c|c|c|}
\hline & & All men & Cancer & Benign \\
\hline \multirow[t]{4}{*}{ Age, yr } & $<50(\%)$ & $53(2.4)$ & $17(2.4)$ & $36(2.4)$ \\
\hline & 50-59 (\%) & $498(22.6)$ & 139 (19.4) & $359(24.1)$ \\
\hline & $60-69(\%)$ & $939(42.6)$ & $305(42.6)$ & $634(42.6)$ \\
\hline & $>70$ (\%) & 714 (32.4) & 255 (35.6) & 459 (30.9) \\
\hline \multirow[t]{2}{*}{ Initial PSA, ng/ml } & Mean (SD) & $4.4(2.6)$ & $5.2(2.6)$ & $4.0(2.5)$ \\
\hline & Median (IQR) ${ }^{\dagger}$ & $4.1(4.2)$ & $5.2(4.1)$ & $3.6(4.0)$ \\
\hline \multirow[t]{2}{*}{ Last PSA, ng/ml } & Mean $(\mathrm{SD})^{*}$ & $18.6(86.2)$ & $44.4(147.7)$ & $6.1(7.4)$ \\
\hline & Median $(\mathrm{IQR})^{\dagger}$ & $6.3(8.5)$ & $11.7(15.4)$ & $4.7(6.1)$ \\
\hline \multirow[t]{2}{*}{ No. of PSA tests } & Mean (SD) & $5.3(2.6)$ & $5.9(3.3)$ & $5.0(2.2)$ \\
\hline & Median $(\mathrm{IQR})^{\dagger}$ & $4.0(3.0)$ & $5.0(3.0)$ & $4.0(3.0)$ \\
\hline \multirow[t]{2}{*}{ Time from first to last PSA, yr } & Mean (SD) & $4.1(1.8)$ & $4.3(1.9)$ & $4.0(1.7)$ \\
\hline & Median (IQR) ${ }^{\dagger}$ & $3.9(2.9)$ & $4.1(3.1)$ & $3.7(2.8)$ \\
\hline
\end{tabular}

Table 2 - Mean and median PSA velocity (PSAV) by method of PSAV calculation

\begin{tabular}{|c|c|c|c|}
\hline PSAV method, ng/ml/yr & All men & Cancer & Benign \\
\hline & \multicolumn{3}{|c|}{ Mean PSAV (SD) } \\
\hline Arithmetric equation & $2.65(21.68)^{*}$ & $7.60(32.89)^{\dagger}$ & $0.26(12.55)^{\dagger}$ \\
\hline Linear regression & $3.81(25.99)^{*}$ & $10.38(44.81)^{\dagger}$ & $0.64(2.14)^{\dagger}$ \\
\hline \multirow[t]{2}{*}{ First last only } & $4.04(28.51)^{*}$ & $11.30(49.16)^{\dagger}$ & $0.55(2.19)^{\dagger}$ \\
\hline & \multicolumn{3}{|c|}{ Median PSAV (IQR) } \\
\hline Arithmetric equation & $0.47(1.63)$ & $1.30(3.06)^{\ddagger}$ & $0.22(1.15)^{\ddagger}$ \\
\hline Linear regression & $0.46(1.50)$ & $1.47(3.32)^{\ddagger}$ & $0.21(0.86)^{\ddagger}$ \\
\hline First last only & $0.39(1.44)$ & $1.50(3.34)^{\ddagger}$ & $0.17(0.83)^{\ddagger}$ \\
\hline \multicolumn{4}{|c|}{$\begin{array}{l}\mathrm{SD}=\text { standard deviation; } \mathrm{IQR}=\text { interquartile range; } \mathrm{AE}=\text { arithmetic equation; } \mathrm{LR}=\text { linear regression; } \mathrm{FL}=\text { first last only. } \\
p<0.001, t \text { test for equality between methods }(\mathrm{AE} / \mathrm{LR}, \mathrm{AE} / \mathrm{FL}, \mathrm{LR} / \mathrm{FL}) . \\
p<0.001, t \text { test for equality in cancer and benign disease. } \\
p<0.001 \text {, Mann-Whitney } \mathrm{U} \text { test for equality in cancer and benign disease. }\end{array}$} \\
\hline
\end{tabular}


Table 3 - Predictive value of PSA velocity (PSAV) cutoffs of $\geq 0.75 \mathrm{ng} / \mathrm{ml} / \mathrm{yr}$ and $\geq 0.0 \mathrm{ng} / \mathrm{ml} / \mathrm{yr}$ for prostate cancer diagnosis, by three methods of PSAV calculation

\begin{tabular}{lccccc}
\hline PSAV method & AE & LR & FL & AE & LR \\
\hline PSAV cutoff, ng/ml/yr & & 0.75 & & 0.0 & \\
Sensitivity, \% & 65.0 & 68.7 & 68.9 & 85.3 & 89.2 \\
Specificity, \% & 69.3 & 73.3 & 74.8 & 32.5 & 30.4 \\
Positive predictive value, \% & 50.3 & 55.3 & 56.8 & 37.8 & 38.2 \\
Negative predictive value, \% & 80.6 & 83.0 & 83.3 & 82.2 & 85.5 \\
\hline AE = arithmetic equation; LR = linear regression; FL = first last only. & & & \\
\hline
\end{tabular}

disease (66.9 vs. $65.6 \mathrm{yr}$, respectively, $p<0.01$ ), as was initial PSA, last PSA before diagnosis, total number of PSA tests, and time from first to last PSA (Table 1).

PSAV calculated by the three methods in all men, those with prostate cancer and benign disease, are demonstrated in Table 2. In all men, there was a marked difference in mean PSAV calculated by each method. The median PSAVs by each method were similar (Table 2). The mean and median PSAVs clearly differed in men with cancer compared to benign disease, irrespective of the method of calculation.

Comparison of PSAV values calculated in each individual by the LR and AE methods, and by the FL and AE methods $(p<0.001$, Wilcoxon signed rank test) showed noticeable differences, but comparison of LR and FL methods did not ( $p=0.21$, Wilcoxon signed rank test). The mean and median differences in PSAV calculated by the LR and AE methods were 2.54 and $0.28 \mathrm{ng} / \mathrm{ml} / \mathrm{yr}$, respectively, with $38.5 \%$ of men having a difference of $\geq 0.5 \mathrm{ng} / \mathrm{ml} / \mathrm{yr}$. The difference in PSAV calculated by these two methods was negatively correlated with the minimum time interval between consecutive PSA tests $(r=-0.19$, $p<0.001$ ). When only cases with a minimum time interval of $\geq 9$ months between consecutive tests were considered, the mean and median differences decreased to 0.71 and $0.14 \mathrm{ng} / \mathrm{ml} / \mathrm{yr}$, respectively. Results were generally similar when the FL and AE methods were compared, with a mean and median difference of 3.14 and $0.38 \mathrm{ng} / \mathrm{ml} / \mathrm{yr}$, respectively. The PSAV values calculated by the LR and FL methods were more comparable, with a mean and median difference of 0.99 and $0.14 \mathrm{ng} / \mathrm{ml} / \mathrm{yr}$, respectively; however, $20.8 \%$ of men still had a difference of $\geq 0.5 \mathrm{ng} / \mathrm{ml} / \mathrm{yr}$. Using a PSAV cutoff of $0.75 \mathrm{ng} / \mathrm{ml} /$ yr, we demonstrated a strong agreement for cancer diagnosis between LR and FL (kappa $=0.85$ ), with a weaker agreement between LR/AE, and FL/AE (kappa $=0.69$ and 0.66 , respectively).

The test characteristics of all methods of calculating PSAV are presented in Table 3 and Fig. 2. Data are shown for the traditional PSAV cutoff of
$0.75 \mathrm{ng} / \mathrm{ml} / \mathrm{yr}$ [3] and a low cutoff of $0.0 \mathrm{ng} / \mathrm{ml} / \mathrm{yr}$ (Table 3). The lower PSAV cutoff had a higher sensitivity compared to $0.75 \mathrm{ng} / \mathrm{ml} / \mathrm{yr}(85-90 \%)$, but at the expense of a much lower specificity (30\%). At both PSAV cutoffs examined, the LR and FL methods demonstrated similar positive and negative predictive values, which were higher than for the AE method. This pattern is likely to continue irrespective of the PSAV cutoff chosen, as can be demonstrated from the individual ROC curves (Fig. 2). The LR and FL methods had a higher area under the curve (AUC) compared to the AE method (0.75 [0.73-0.77] and 0.76 [0.74-0.79] vs. 0.71 [0.69$0.73]$, respectively, $p<0.001$ ).

\section{Discussion}

This study confirms that PSAV is higher in men with prostate cancer compared to benign disease (Table 2), irrespective of the method of PSAV calculation [3-6]. However, we also demonstrated that an individual PSAV result can differ substantially depending on the method of calculation. In light of the current confusion regarding the clinical

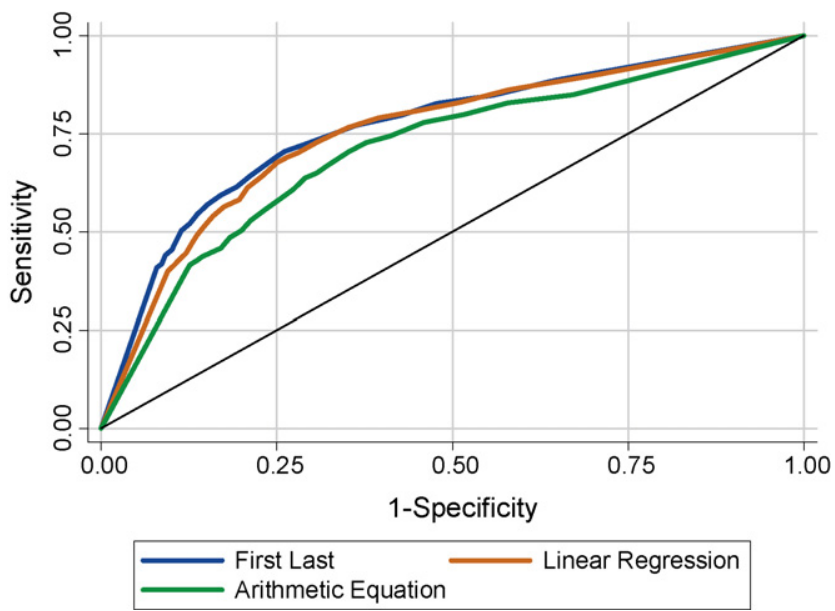

Fig. 2 - Receiver operating characteristic curves of three methods of prostate-specific antigen (PSA) velocity calculation for prostate cancer diagnosis. 
usefulness of PSAV [15], using a standardised method of PSAV calculation may be helpful when evaluating studies from different populations. Further, results from studies on PSAV that use different methods of PSAV calculation may not be directly comparable $[3-7,9-11,14]$. It is possible that study findings may not be reproduced in clinical practice if the method of PSAV calculation varies. For individual men, this could influence the decision to proceed with prostate biopsy.

Strengths of this study include that it is population-based with a large number of participants. The methods of calculation assessed are those commonly used in the literature; therefore, the findings and their implications will be broadly applicable in research and clinical settings. The study has limitations worthy of note. It is possible that errors in data collection, in data entry, or during the matching process might have resulted in missed PSA or diagnostic data. Internal validation procedures in the NICR ensure that these errors are very uncommon and therefore unlikely to significantly affect results. Secondly, different PSA assay platforms were used during the study period, which, given their inherent variability, might not provide results that are directly comparable and might affect the PSAV results observed. Although this may affect the precision of each PSA value, as the PSAV by each method was calculated from the same PSA data, it will not affect the comparison between methods. Thirdly, men were investigated at the discretion of their own clinician. The decision to proceed to prostate biopsy and biopsy technique are likely to have varied between clinicians, which may influence the cancer diagnosis rates observed. Further, not all men with similar PSA and PSAV values underwent investigation. Men who did not proceed to definite diagnosis $(91.1 \%)$ were younger $(64.8 \mathrm{yr}$, $p<0.001)$, with lower mean initial PSA $(2.4 \mathrm{ng} / \mathrm{ml}$, $p<0.001)$, final PSA $(4.0 \mathrm{ng} / \mathrm{ml}, p<0.001)$, number of PSA tests (4.4, $p<0.001)$, and lower mean and median PSAVs $(0.41 \mathrm{ng} / \mathrm{ml} / \mathrm{yr}$ and $0.02 \mathrm{ng} / \mathrm{ml} / \mathrm{yr}$, respectively) compared to those who were included (Table 1). It is not surprising that these men, with a low initial PSA and relatively stable repeat PSA levels, did not proceed to biopsy. There may therefore be a selection bias towards investigated men; the results observed may have differed if all men had proceeded to prostate biopsy. Lastly, clinical information on the men was not available, which prevents inferences being made about how factors such as the reason for PSA testing, family history, medications, rectal examination findings, or prostate volume on transrectal ultrasound might have influenced PSA changes or cancer diagnosis.
The differing PSAV results using the three methods may, in large part, be due to PSA variability and the time interval between tests. Short-term variations in PSA are common $[3,16,17]$ and, although factors such as infection and prostatic manipulation can artificially increase the PSA value [18], there is also an inherent biologic variability of PSA. A recent systematic review including 12 studies that examined PSA variability estimated the mean variation between tests to be $20 \%(\sim 33 \%$ at $95 \%$ confidence interval) [17]. A true PSA of $4.5 \mathrm{ng} / \mathrm{ml}$ may therefore produce measured PSA results ranging from $3.0-6.0 \mathrm{ng} / \mathrm{ml}$. By using only two values to calculate PSAV (FL) [9-11], it is assumed that each value lies close to the true PSA. Measured PSA values at the upper or lower limits of variability may produce a misleading PSAV, even when these are taken over a long time period, as occurred in the studies from the European Randomised Study of Screening for Prostate Cancer [9-11]. This potential problem can be illustrated in Fig. 1c. As the second and third PSA values are taken within 3 mo of the first and last PSA tests, respectively, they are unlikely to represent true changes in PSA. However, if the second and third PSA values were used to calculate PSAV instead of the first and last values, the PSAV result would be $2.28 \mathrm{ng} / \mathrm{ml} / \mathrm{yr}$ as opposed to $0.72 \mathrm{ng} / \mathrm{ml} / \mathrm{yr}$. Hence, using three or more PSA tests will better reflect true PSA change [14].

The relationship between PSAV and testing interval has been described previously [14]. As PSAV, using the AE method, is calculated as the mean of consecutive velocities between PSA tests, each individual PSA change has equal importance (Fig. 1a). Therefore, this PSAV may be affected more by short-term changes in PSA as opposed to the overall trend. In the current study, there was no minimum time limit between individual tests applied, and indeed short time intervals did distort the calculated PSAV. Longer time intervals (9-12 mo) have been recommended as they are more likely to represent true changes in PSA [14]. In screening studies $[4,6]$ or studies using stored sera $[3,14]$ in which PSA samples are taken annually or biannually, the PSAV calculated by AE will be similar to that of LR. However, regular time intervals between PSA tests may not occur in clinical practice, particularly given recent recommendations to repeat an abnormal PSA before proceeding with invasive investigations $[16,17]$. In this population-based study, only $11.6 \%$ of men had at least 9 mo between each PSA, limiting the widespread usefulness of PSAV if strict time constraints are applied.

Recently, D'Amico et al $[19,20]$ proposed calculating PSAV using only PSA values confined to the year 
before cancer diagnosis. As PSA from prostate cancer is likely to be increasing exponentially during this time period [3], there will be less contribution from benign sources of PSA, suggesting PSA change may be a better indicator of cancer biology. With the use of this method, a PSAV of $\geq 2.0 \mathrm{ng} / \mathrm{ml} / \mathrm{yr}$ was associated with an increased risk of prostate cancer specific and overall mortality following radical prostatectomy or radiotherapy $[19,20]$. However, this method may not be ideal. As the PSA tests have to be separated by a minimum of $6 \mathrm{mo}$, in the majority of cases, only two PSA values are used to calculate PSAV. Although LR analysis was used to calculate PSAV in these studies, when there are only two PSA values, this is equivalent to the FL method. Also, as the time period in which PSAV is calculated is less than $1 \mathrm{yr}$, PSA changes may be simply due to PSA variability as opposed to signifying cancer aggressiveness (as described above, a measured PSA can "increase" from $3.0 \mathrm{ng} / \mathrm{ml}$ to $6.0 \mathrm{ng} / \mathrm{ml}$ because of PSA variability even when the true PSA remains at $4.5 \mathrm{ng} / \mathrm{ml}$ ). Within a large study population, these changes due to variability will not greatly affect overall results. However, at an individual level, a high PSAV calculated with this method may not necessarily indicate aggressive disease. The optimal number of PSA tests and time interval before diagnosis by which PSAV most accurately reflects tumor biology are unknown. Also, the ability of PSAV calculated using only PSA values from the year before diagnosis to differentiate between cancer and benign disease has not yet been established.

Other studies have demonstrated the importance of the method for calculating PSA kinetics. Benecchi [21] assessed the utility of PSAV (AE method) and PSA slope (LR method) in diagnosing prostate cancer in 312 men from a single center. PSA slope had improved sensitivity and specificity compared to PSAV, with a higher AUC on ROC analysis (0.66 vs. $0.74)$. These results are comparable with this report (Table 3), although the current study has the advantage of being population-based with a large number of participants. In addition, we also assessed the FL method for calculating PSAV. Svatek et al [22] compared methods of calculating PSA doubling time (PSADT), namely the LR and FL methods, with random coefficient models whereby each individual's calculated PSADT borrows strength from the population data, leading to a more accurate PSADT estimate. In 122 men with androgen-independent prostate cancer, random coefficient models appeared to provide a better fit to the PSA data compared to linear methods, and to better predict survival in this patient population.
Further investigation is needed to assess the utility of these methods using PSA data before cancer diagnosis.

\section{Conclusions}

The method used to calculate PSAV can produce markedly different results from the same PSA data, which may affect the decision to proceed with prostate biopsy. Linear regression analysis using all PSA values is less influenced by short-term PSA variability and should be the method of choice for calculating PSAV. Using the first and last PSA values only, which is easier to calculate with a similar predictive value, may be adequate for everyday clinical use, as long as the measurements are separated by a sufficiently long time period.

\section{Conflicts of interest}

The authors have nothing to disclose.

\section{Acknowledgements}

This research is funded by the Northern Ireland Research and Development Office and by the Men Against Cancer charity. The Northern Ireland Cancer Registry is funded by the Department of Health, Social Services \& Public Safety Northern Ireland (DHSSPSNI).

\section{References}

[1] Catalona WJ, Loeb S. The PSA era is not over for prostate cancer. Eur Urol 2005;48:541-5.

[2] Stamey TA, Yang N, Hay AR, et al. Prostate-specific antigen as a serum marker for adenocarcinoma of the prostate. N Engl J Med 1987;317:909-16.

[3] Carter HB, Pearson JD, Metter EJ, et al. Longitudinal evaluation of prostate-specific antigen levels in men with and without prostate disease. JAMA 1992;267:2215-20.

[4] Smith DS, Catalona WJ. Rate of change in serum prostate specific antigen levels as a method for prostate cancer detection. J Urol 1994;152:1163-7.

[5] Mettlin C, Murphy GP, Lee F, et al. Characteristics of prostate cancer detected in the American Cancer Society-National Prostate Cancer Detection Project. J Urol 1994;152(5 pt 2):1737-40.

[6] Berger AP, Deibl M, Steiner H, et al. Longitudinal PSA changes in men with and without prostate cancer: assessment of prostate cancer risk. Prostate 2005;64:240-5.

[7] Fang J, Metter EJ, Landis P, et al. PSA velocity for assessing prostate cancer risk in men with PSA levels between 
2.0 and $4.0 \mathrm{ng} / \mathrm{ml}$. Urology 2002;59:889-93, discussion 893-4.

[8] Loeb S, Roehl KA, Graif T, et al. PSA velocity threshold for predicting prostate cancer in young men with PSA $<4$ ng/ml. J Urol 2006;175(4 Suppl):153.

[9] Raaijmakers R, Wildhagen MF, Ito K, et al. Prostate-specific antigen change in the European Randomized Study of Screening for Prostate Cancer, section Rotterdam. Urology 2004;63:316-20.

[10] Roobol MJ, Kranse R, de Koning HJ, et al. Prostate-specific antigen velocity at low prostate-specific antigen levels as screening tool for prostate cancer: results of second screening round of ERSPC (Rotterdam). Urology 2004; 63:309-13, discussion 313-5.

[11] Schröder FH, Roobol MJ, van der Kwast TH, et al. Does PSA velocity predict prostate cancer in pre-screened populations? Eur Urol 2006;49:460-5 (discussion 465).

[12] Northern Ireland Statistics and Research Agency. Northern Ireland Census 2001 Key Statistics. Belfast: National Statistics; 2002. Available at: http://www.nisranew.nisra. gov.uk/census/Census2001Output/KeyStatistics/keystats. html. Accessed on 18 September 2006.

[13] Gavin A, McCarron P, Middleton RJ, et al. Evidence of prostate cancer screening in a UK region. BJU Int 2004;93: 730-4.

[14] Carter HB, Pearson JD, Waclawiw Z, et al. Prostate-specific antigen variability in men without prostate cancer: effect of sampling interval on prostate-specific antigen velocity. Urology 1995;45:591-6.
[15] Perrin P. PSA velocity and prostate cancer detection: the absence of evidence is not the evidence of absence. Eur Urol 2006;49:418-9.

[16] Eastham JA, Riedel E, Scardino PT, et al. Variation of serum prostate-specific antigen levels: an evaluation of year-to-year fluctuations. JAMA 2003;289:2695700.

[17] Soletormos G, Semjonow A, Sibley PE, et al. Biological variation of total prostate-specific antigen: a survey of published estimates and consequences for clinical practice. Clin Chem 2005;51:1342-51.

[18] Collins GN, Martin PJ, Wynn-Davies A, et al. The effect of digital rectal examination, flexible cystoscopy and prostatic biopsy on free and total prostate specific antigen, and the free-to-total prostate specific antigen ratio in clinical practice. J Urol 1997;157:1744-7.

[19] D'Amico AV, Chen MH, Roehl KA, et al. Preoperative PSA velocity and the risk of death from prostate cancer after radical prostatectomy. N Engl J Med 2004;351: 125-35.

[20] D'Amico AV, Renshaw AA, Sussman B, et al. Pretreatment PSA velocity and risk of death from prostate cancer following external beam radiation therapy. JAMA 2005;294:440-7.

[21] Benecchi L. PSA velocity and PSA slope. Prostate Cancer Prostatic Dis 2006;9:169-72.

[22] Svatek RS, Shulman M, Choudhary PK, et al. Critical analysis of prostate-specific antigen doubling time calculation methodology. Cancer 2006;106:1047-53.

\section{Editorial Comment \\ Scott Eggener, \\ Memorial Sloan-Kettering Cancer Center, New York, NY, United States \\ eggeners@mskcc.org}

"Now that we've got PSA velocity, what are we going to do with it"

Prostate-specific antigen velocity (PSAV) was introduced nearly $15 \mathrm{yr}$ ago as men diagnosed with prostate cancer were found to exhibit more rapid rises in PSA years prior to their diagnosis compared to those without clinically evident prostate cancer [1]. Recently, interest in PSAV has been rekindled, because the rate of PSA change in the year prior to radical prostatectomy or radiation therapy has been directly associated with the likelihood of disease-specific death $[2,3]$.

Although these and other studies have generated much "publicity" for PSAV, physicians still lack sound guidance on whether, or how, to use PSAV in clinical practice. For instance, debate exists whether PSAV is a valuable adjunct to PSA alone to determine prostate cancer risk $[4,5]$ or prompt diagnostic procedures. Further, in men considering treatment options or, alternatively, following primary therapy, how should pretreatment PSAV be appropriately integrated into their care? Should a markedly elevated level prompt multimodal therapy, a lower threshold for instituting secondary therapies, or not be considered at all? Simply and concisely, we do not know.

This article, similar to another publication [6], shows that formulas used to calculate PSAV are generally inconsistent and highlights that as we continue to decipher the appropriate role for PSAV, a uniform methodologic language is mandatory.

Linear regression has been anointed the de facto "gold standard" to calculate PSAV. With adequate measurements over an adequate period of time (both yet to be definitively determined), linear regression is assumed to best control for shortterm physiologic fluctuations in serum PSA levels and most fairly represent the "big-picture" PSAV. However, as a point-of-care tool, not all physicians have the resources to quickly perform linear regression. This study suggests a simple arithmetic method that may suffice.

Studies like this should trigger further work to explore how PSAV is affected by the absolute PSA, 
prostate volume, interval between PSA levels, total number of PSA levels, and time period over which it is calculated [6].

As we continue to sort out PSAV methodology, it cannot be overemphasized that the more pressing issue is how to intelligently implement PSAV so that the care of patients who seek our advice may be substantially improved.

\section{References}

[1] Carter HB, et al. Longitudinal evaluation of prostatespecific antigen levels in men with and without prostate disease. JAMA 1992;267:2215-20.
[2] D'Amico AV, et al. Preoperative PSA velocity and the risk of death from prostate cancer after radical prostatectomy. N Engl J Med 2004;351:125-35.

[3] D'Amico AV, et al. Pretreatment PSA velocity and risk of death from prostate cancer following external beam radiation therapy. JAMA 2005;294:440-7.

[4] Perrin P. PSA velocity and prostate cancer detection: the absence of evidence is not the evidence of absence. Eur Urol 2006;49:418-9.

[5] Thompson IM, et al. Assessing prostate cancer risk: results from the Prostate Cancer Prevention Trial. J Natl Cancer Inst 2006;98:529-34.

[6] Yu X, et al. Comparison of methods for calculating prostate specific antigen velocity. J Urol 2006;176: 2427-31. 